\title{
LA BUENA FE PROCESAL Y EL DEBER DE COLABORACIÓN DE LAS PARTES EN LOS PROCEDIMIENTOS LABORALES
}

\author{
MARÍA MATILDE LARROUCAU GARCÍA \\ Universidad de Chile
}

\begin{abstract}
RESUMEN: En la presente monografía se pretende analizar cuál es el rol que debe jugar la buena fe procesal dentro del proceso civil general y más específicamente dentro del nuevo procedimiento laboral chileno. Para ello, junto con intentar una aproximación doctrinaria de dicho concepto y determinar luego cómo este ha sido plasmado en las normas de nuestro Código del Trabajo, se intenta contrastar dicha noción con la de un proceso civil armonioso con la debida protección de los derechos de los ciudadanos.
\end{abstract}

Palabras clave: Buena fe procesal, garantias constitucionales, procedimiento laboral.

ABSTRACT: This monograph analyze what is the role of the procedural good faith in the general civil process, and more specifically in the new Chilean labor procedure. To accomplish this, along with trying a doctrinal approach of this concept and establish how procedural good faith has been embodied in the standards of our Labor Code, this notion is contrasted with the notion of a harmonious civil process, with the proper protection of the citizens rights.

Key Words: Procedural good faith, constitutional rights, labor procedure.

\section{INTRODUCCIÓN}

La incorporación y el reconocimiento expreso de exigencias de comportamiento de buena fe para las partes intervinientes en el proceso, dentro de los distintos ordenamientos procesales civiles europeos y latinoamericanos, es un fenómeno que se ha venido desarrollando desde finales del siglo XIX ${ }^{1,2}$.

Hasta ese momento histórico, y ya analizando nuestro propio contexto nacional, tenemos que, respecto de lo ocurrido con nuestro CPC, este, en razón de su innegable influencia decimonónica ${ }^{3}$, no hace referencia alguna y no consagra expresamente exigencias genéricas o generales de adecuación de conducta de las partes a un modo acorde con la buena fe procesal, y se limita únicamente a sancionar, bajo supuestos aislados, ciertas conductas procesales, ya sea mediante la desestimación de la pretensión, o bien ya sea

\footnotetext{
1 Gorigoitfa ABOTT, Felipe, "La buena fe en el proceso civil chileno", en: Revista Nomos, N², 2008, Universidad de Viña del Mar, p. 133.

${ }^{2}$ Ejemplos de ordenamientos procesales civiles que han incluido para las partes intervinientes en el proceso comportamientos de buena fe son: la Ley de Enjuiciamiento Civil Española, que en su artículo 247 señala: "los intervinientes en todo tipo de procesos deberán ajustarse en sus actuaciones a la regla de la buena fe”; el parágrafo 138 del Código Procesal Civil Alemán, que señala: "Deber de declaración sobre los hechos; deber de decir verdad. 1) Las partes deben hacer sus declaraciones sobre cuestiones de hecho en forma completa y adecuada a la verdad"; y en Latinoamérica, el Código Procesal Civil Peruano, que en su artículo 4, inciso 2, dispone: "las partes, sus representantes, sus abogados, y en general, todos los partícipes del proceso, adecuan sus conductas a los deberes de veracidad, probidad, lealtad y buena fe".

${ }^{3}$ No se puede obviar que el mayor y principal referente de nuestro CPC, lo constituyó la Ley de Enjuiciamiento Civil Española de 1855 .
} 
mediante la imposición de costas o una multa ${ }^{4}$. Ejemplo de lo anterior es lo dispuesto en el artículo 88 del CPC, que permite imponer el aumento de hasta el doble del depósito necesario para promover un nuevo incidente, en el caso que una de las partes haya promovido y perdido dos incidentes anteriormente 5 . Algo similar ocurría respecto de los otros procedimientos civiles nacionales ${ }^{6}$.

Sin embargo, siguiendo la tendencia observada, nuestra realidad normativa no ha podido mantenerse alejada de los influjos e inspiraciones moralizantes del proceso y así se ha plasmado en las reformas realizadas en los últimos años a los distintos procedimientos civiles reglados en nuestro ordenamiento jurídico, pudiendo encontrar una primera aproximación a la buena fe procesal en la reforma llevada a cabo respecto del procedimiento laboral ${ }^{7}$. En esa misma línea, y más actualmente, encontramos lo establecido en el anteproyecto al CPC, que incorpora en su artículo $8^{\circ}$ una referencia expresa al deber de buena fe procesal ${ }^{8}$.

Como se seńaló anteriormente, es nuestro Código del Trabajo, el primer cuerpo normativo procesal civil chileno que establece una exigencia genérica expresa de actuación conforme a la buena fe dentro del proceso laboral, de acuerdo con lo prescrito en los artículos 425 y 430 de dicho cuerpo legal.

La primera de dichas normas consagra a la buena fe procesal como un principio informante de los nuevos procedimientos laborales al señalar que "Los procedimientos del trabajo serán orales, públicos y concentrados. Primarán en ellos los principios de la inmediación, impulso procesal de oficio, celeridad, buena fe, bilateralidad de la audiencia y gratuidad". Por su parte, el artículo 430, faculta al tribunal para la adopción de todas

\footnotetext{
${ }^{4}$ Gorigoitia ABOTT, Felipe, op. cit., p. 134.

${ }^{5}$ El artículo 88 del CPC dispone expresamente: "La parte que haya promovido y perdido dos o más incidentes en un mismo juicio, no podrá promover ningún otro sin que previamente deposite en la cuenta corriente del tribunal la cantidad que este fije. Para los efectos de efectuar esa consignación, el tribunal de oficio en la resolución que deseche el segundo incidente deberá determinar el monto del depósito, el que deberá fluctuar entre una y diez unidades tributarias mensuales y se aplicará como multa a beneficio fiscal si fuere rechazado el nuevo incidente promovido. El tribunal determinará el monto del depósito considerando la actuación procesal de la parte y si observare mala fe en la interposición de nuevos incidentes podrá aumentar su cuantía hasta por el duplo".

${ }^{6}$ Así, por ejemplo, el antiguo título $\mathrm{V}$ de nuestro Código del Trabajo no establecía de modo genérico deberes de buena fe para las partes en el proceso, a diferencia de lo que ocurre hoy con posterioridad a la reforma llevada a cabo mediante las leyes 20.087 y 20.260 .

7 En efecto, si bien la primera gran modificación experimentada por el procedimiento civil chileno, entendido este en términos generales, fue la verificada en el procedimiento civil de familia, mediante la Ley 19.968, y sus posteriores modificaciones, ellas, a diferencia de las recientes modificaciones a los procedimientos laborales, no contienen mención alguna respecto del denominado principio de la buena fe procesal.

${ }^{8} \mathrm{El}$ referido artículo del Anteproyecto de Código Procesal Civil, prescribe: "ARTÍ́CULO $8^{\circ}$.- BUENA FE PROCESAL: Las partes, los terceros, y general, todos quienes deben acudir ante los tribunales deben ajustar su conducta a la dignidad de la justicia, al respeto de los derechos fundamentales de la persona humana y a la lealtad y buena fe procesal. El tribunal, de oficio o a petición de partes, podrá adoptar durante el desarrollo del proceso todas las medidas que estime pertinentes para impedir o sancionar toda conducta u omisión que importe un fraude procesal, colusión o cualquiera otra conducta ilícita o dilatoria. Si los tribunales estimaren que alguna de las partes o tercero han actuado conculcando las reglas de la buena fe procesal, podrá imponerle, de forma motivada, y respetando el principio de proporcionalidad, una multa entre 10 y 100 UTM. En ningún caso la multa podrá superar la tercera parte de la cuantía del litigio. En caso de reincidencia, se podrá aplicar el doble de la multa. Para determinar la cuantía de la multa el tribunal deberá tener en cuenta las circunstancias de hecho que se trate, así como los perjuicios que al procedimiento o a las otras partes se hubieren podido causar".
} 
aquellas medidas necesarias para evitar el fraude, la colusión, el abuso del derecho y las actuaciones dilatorias, finalizando, en su inciso tercero, definiendo qué ha de entenderse por actuaciones dilatorias 9 .

Las normas aludidas fueron recogidas inicialmente en el mensaje presidencial que dio inicio a la reforma de los procedimientos laborales con la Ley 20.087, siendo objeto de posteriores modificaciones hasta quedar del modo hoy día consagradas ${ }^{10}$, sin embargo, como se desprende de su claro tenor literal, en ninguna de ellas se hace referencia ni se define por el legislador qué debemos entender por buena fe procesal, razón por la cual, a fin de poder analizar y precisar en qué forma ha sido recogida dicha noción en nuestro Código del Trabajo, es necesario primeramente intentar esbozar una definición de la misma.

\section{APROXIMACIÓN A UNA DEFINICIÓN DE BUENA FE PROCESAL}

Dado que nuestro legislador laboral no estableció un concepto de la buena fe procesal, y sin entrar a justificar aún ni la bondad ni el perjuicio que ello acarrea, ha correspondido a la doctrina elaborar un concepto de buena fe que haga aplicables las prescripciones contenidas en los diversos códigos.

La buena fe procesal ha sido definida como "aquel principio que impone a las partes litigantes un deber de rectitud, honradez y buen proceder en la defensa de sus intereses jurídicos dentro de un proceso judicial" 11.

Picó i Junoy, a su vez, lo define como "aquella conducta exigible a toda persona en el marco de un proceso, por ser socialmente admitida como correcta" 12 .

En el mismo sentido, Núnez lo define como "el principio de acuerdo al cual las partes deben formular sus declaraciones sobre las circunstancias fácticas íntegramente y de acuerdo a la realidad de los hechos"13.

\footnotetext{
9 El artículo 430 del CT dispone, "Los actos procesales deberán ejecutarse de buena fe, facultándose al tribunal para adoptar las medidas necesarias para impedir el fraude, la colusión, el abuso del derecho y las actuaciones dilatorias. El juez podrá rechazar de plano aquellas actuaciones que considere dilatorias. Se entenderá por actuaciones dilatorias todas aquellas que son el solo objeto de demorar la prosecución del juicio sean intentadas por alguna de las partes. De la resolución que declare como tal alguna actuación, la parte afectada podrá reponer para que sea resuelta en la misma audiencia".

${ }^{10}$ En efecto, respecto del artículo $430 \mathrm{del}$ CT, se verificaron diversas discusiones, siendo de trascendencia la indicación efectuada por los diputados Ceroni, Bustos y Pérez Lobos, para intentar incorporar al artículo un inciso final que disponía "si tres actuaciones fueren declaradas como dilatorias, y la reposición, si se presentare, fuere rechazada, el juez podrá imponer una multa de una a quince unidades tributarias mensuales a la parte que las hubiera intentado". Sin embargo, como puede observarse del texto actual del referido artículo, dicha indicación no prosperó.

11 Benftez Ramfrez, Eugenio, "Reflexiones en torno a la propuesta de reforma al Procedimiento Civil Chileno: II. Principios Procesales relativos a las partes", en: Revista Chilena de Derecho, vol. 34, $\mathrm{N}^{\circ} 3,2007$ a las partes, p. 3. Disponible en:

http://www.scielo.cl/scielo.php?pid=S0718-34372007000300014\&script=sci_arttext [consultado el 10 de noviembre de 2009].

12 PICO I JUNOY, Joan, El principio de la buena fe procesal, p. 19. Disponible en: http://www.justiciayderecho.org/revista4/ articulos/EL\%20PRINCIPIO\%20DE\%20LA\%20BUENA\%20FE\%20PROCESAL\%20Joan\%20Pico\%20i\%20Junoi.pdf

${ }^{13}$ NÚNÉz OJeda, Raúl, citado por Hunter AMPUero, Iván, "No hay buena fe sin interés: La buena fe procesal y los deberes de veracidad, completitud y colaboración", en: Revista de Derecho, vol. XXI, N², 2008, p. 4. Disponible en: http://www.scielo.cl/pdf/revider/v2 $\ln 2 /$ art07.pdf [consultada 8 de noviembre de 2009].
} 
Finalmente, Palavecino lo define como "un principio conforme al cual las partes tendrían un deber de probidad, lealtad, colaboración con la justicia y veracidad de los actos procesales"14.

Por otra parte, como se desprende de la última definición transcrita, manifestaciones de este principio, u otros deberes derivados del mismo serían, siguiendo a Hunter, el deber de veracidad, consistente en no alegar como existentes hechos que se saben inexistentes y, al mismo tiempo, no negar hechos que se saben inexistentes; el deber de completitud en las alegaciones, que significa a su vez el alegar todos los hechos relevantes para la correcta resolución del conflicto sin omitir dato alguno que recaiga bajo el dominio de la parte; y por último, el deber de colaboración, que precisa un esfuerzo conjunto de las partes para buscar con el juez la justa y pronta solución del conflicto, y cuya manifestación principal sería la de acompañar al procedimiento todos los medios de prueba al alcance de la parte ${ }^{15}$.

Como puede apreciarse, y siendo las definiciones expuestas solo una selección al azar de las elaboraciones doctrinarias al respecto, es posible sostener que existen y existirán tantas definiciones de buena fe procesal, como estudiosos del Derecho, sin embargo, de todas estas puede desprenderse claramente, como elemento común, que reflejan innegablemente el alto contenido axiológico, ético y moral que comprende el concepto de buena fe procesal.

Lo anterior se muestra además en el hecho de que la unanimidad de la doctrina concuerda en señalar que la buena fe procesal es un concepto jurídico indeterminado, lo que desde ya nos advierte del gran nivel de incertidumbre que el referido concepto conlleva, y nos evidencia, además, el conflicto que ineludiblemente dicho concepto enfrenta con la certeza jurídica, por cuanto, tratándose de un concepto que es reflejo de una valoración social en constante cambio y, en consecuencia, poseedora de una naturaleza constantemente dinámica, será imposible fijar su contenido con la debida precisión y permanencia a través de reglas genéricas que permitan establecer un estándar claro acerca de lo que en cada caso será buena o mala fe ${ }^{16}$.

De acuerdo con lo anterior, y aun con el peligro de agravar la situación expuesta, solo nos quedará confiar en lo que resuelva cada juez, en cada caso concreto que se le presente, entregándoles a ellos la posibilidad de que determinen de acuerdo con sus propias concepciones valorativas lo que han de entender por buena $\mathrm{fe}$, valoraciones que, siendo enteramente subjetivas y personales, pueden conllevar el riesgo de que no necesariamente concuerden con aquellas consideradas como válidas para una sociedad determinada en un contexto histórico dado.

En síntesis, siendo la buena fe procesal un concepto tan extenso y difuso, y existiendo además la facultad del juez de exigirle a las partes un comportamiento irrestricto conforme a ella durante todo el desarrollo del proceso, se configura un sistema procesal civil cada vez menos garantista y más limitativo de los derechos de las partes, y en consecuencia completamente alejado de su razón de ser.

\footnotetext{
14 Palavecino CACeres, Claudio, "El retorno del inquisidor. Las porestades judiciales en materia probatoria en el Procedimiento laboral chileno", en: Revista Laboral Chilena, N¹73, enero 2009, Santiago, p. 74.

${ }^{15}$ HUNTER AMPUERO, Iván, op. cit., p. 157 y ss.

16 GorIgorTfA ABOTT, Felipe, op. cit. p. 144.
} 


\section{LA BUENA FE PROCESAL EN EL CÓDIGO DEL TRABAJO}

Como se señaló precedentemente existen en nuestro Código del Trabajo dos normas que recogen la buena fe procesal, a lo menos de modo genérico, esto es, como un principio informante de los nuevos procedimientos, en el artículo $425 \mathrm{CT}$ y, a su vez, en el 430 $\mathrm{CT}$, facultando al juez a adoptar todas aquellas medidas que sean necesarias para evitar la colusión, el fraude, el abuso del derecho y las actuaciones dilatorias.

De principio y haciendo nuestra la crítica formulada por Montero Aroca a propósito de la incorporación en la Ley de Enjuiciamiento Civil española (en adelante LEC) de la buena fe procesal ${ }^{17}$, podemos señalar que, en nuestro Código, al igual que lo ocurrido en España, no obstante señalarse expresamente que la buena fe constituye un principio informante del nuevo procedimiento laboral, en la práctica la referencia no puede calificarse de tal. Ello por dos razones, la primera, por cuanto la noción de principio necesariamente alude a la idea de dualidad y contraposición, que no se verifica en este caso, ya que evidentemente no existe un principio que disponga actuaciones de mala $\mathrm{fe}$, y en segundo lugar, por cuanto de configurarse la buena fe como un principio del procedimiento, necesariamente debiera afectar y ser aplicable y exigible respecto de todos quienes hacen el proceso, incluyendo a los jueces y magistrados. Sin embargo, como puede desprenderse de las disposiciones pertinentes, las normas analizadas se limitan a imponer el deber a algunas de las personas que intervienen en el proceso, como son solo las partes y los profesionales que las defienden, y no al juez ${ }^{18}$.

Siguiendo con el análisis de nuestros procedimientos laborales, tenemos, además, el referido deber de la buena fe que se impone a las partes, en otras normas del Código del Trabajo, que nos llevan a interrogarnos por la forma en que dicho concepto se ha recogido por nuestro legislador.

Las normas pertinentes son los artículos $453 \mathrm{~N}^{\circ} 1$, inciso $7^{19}$, que establece el deber del demandado al contestar la demanda, de tener que negar todos y cada uno de los hechos contenidos en la misma, bajo amenaza de sanción de que se tendrán por tácitamente admitidos aquellos no negados, de lo cual es fácilmente colegible que nos encontramos ante una de las manifestaciones previamente anotadas de la buena fe procesal, como es el deber de completitud, imponiéndole a la parte demandada la obligación de tener que manifestar todos aquellos hechos que sean relevantes para la solución del conflicto no pudiendo omitir dato alguno que caiga sobre su dominio.

\footnotetext{
17 Montero Aroca, Juan, Ideología y proceso civil. Su reflejo en la "buena fe procesal", p. 5. Disponible en: www.cadperu.com/virtual/file.php/1/moddata/data/3/.../IDEOLOGIA.pdf [consultada 8 de noviembre de 2009].

${ }^{18}$ En el mismo sentido se pronuncia Hunter, cuando señala que "la regla de actuación conforme a la buena fe procesal no tiene como destinatario natural al órgano jurisdiccional”. HUNTER AMPUERO, Iván, op. cit., p. 164. Ver también BENITEZ RAMfREZ, Eugenio, op. cit., quien en similar sentido se refiere a la buena fe procesal bajo el parágrafo "II. Principios procesales relativos a las partes".

19 El artículo 453, $\mathrm{N}^{\circ} 1$, inciso séptimo prescribe: "En la audiencia preparatoria se aplicarán las siguientes reglas: $\mathrm{N}^{\circ} .$. Cuando el demandado no contestare la demanda, o de hacerlo no negare en ella algunos de los hechos contendidos en la demanda, el juez, en la sentencia definitiva, podrá estimarlos como tácitamente admitidos".
} 
En el mismo sentido la norma del No 5 del mismo artículo ${ }^{20}$, que regula la exhibición de instrumentos decretada por el tribunal, en cuyo caso de no exhibirse sin causa justificada, podrá estimarse como probadas las alegaciones hechas por la parte contraria en relación con la prueba decretada, deber que parece ser una concreción del denominado deber de colaboración, el cual como se señaló, siguiendo a Hunter ${ }^{21}$, impone a la parte pertinente el deber de colaborar con la contraria y con el juez en la búsqueda de una pronta y justa solución del conflicto, debiendo, en consecuencia, acompañar al procedimiento todos los medios de prueba que se encuentren a su alcance.

Con respecto a la prueba confesional, contemplada en la norma del artículo $454 \mathrm{~N}^{\circ}$ $3^{22}$, de modo similar a lo ya señalado a propósito del artículo $453 \mathrm{~N}^{\circ} 1$ inciso $7^{\circ}$, pareciera ser que se contempla una vez más el denominado deber de completitud, por cuanto de no comparecer el absolvente a la audiencia, o si compareciendo se niega a declarar o se dan respuestas evasivas, se podrá presumir efectivas las alegaciones de la contraria.

Finalmente, respecto de la norma contenida en el artículo $493 \mathrm{CT}^{23}$, puede desprenderse de ella otra manifestación de la buena fe procesal, como sería el deber de colaboración de la parte de aportar todos los medios de prueba a su alcance, producto de la aplicación de las cargas probatorias dinámicas. En efecto, de entenderse que la expresión "indicios suficientes" equivalen no a una presunción sino a menos que prueba, el trabajador estará eximido de probar el hecho basal y dicha carga recaerá en el empleador por entenderse que este tiene un acceso más fácil y directo a los medios de prueba.

Como puede apreciarse, del análisis de las normas descritas, parece evidente que lo que consagra nuestro Código del Trabajo son verdaderos deberes de actuación para las partes orientadas al resguardo de la buena fe en el proceso, situación que como se verá a continuación no solo afecta el principio dispositivo, sino además una serie de garantías constitucionales.

\section{IMPLICANCIA DE LA CONSAGRACIÓN DEL DEBER DE BUENA FE EN EL PROCEDIMIENTO LABORAL}

La idea de la buena fe dentro de un procedimiento, concebida como un deber positivo de actuación conforme a ella, y no únicamente como una abstención de conductas de mala fe, responde a una motivación de fondo, y no a una mera opción técnica del legislador, como se ha señalado en variadas oportunidades. Así Montero Aroca, describe

\footnotetext{
${ }^{20} \mathrm{El}$ artículo 453 No 5, dispone: "La exhibición de instrumentos que hubiere sido ordenada por el tribunal se verificará en la audiencia de juicio. Cuando, sin causa justificada, se omita la presentación de aquellos que legalmente deban obrar en poder de una de las partes, podrán estimarse probadas las alegaciones hechas por la parte contraria en relación con la prueba decretada".

21 HUNTER AMPUERO, Iván, op. cit., p. 157.

22 El artículo 454 No 3 establece en lo pertinente: "Si el llamado a confesar no compareciese a la audiencia sin causa justificada, o compareciendo se negase a declarar o diere respuestas evasivas, podrán presumirse efectivas, en relación a los hechos objeto de prueba, las alegaciones de la parte contraria en la demanda o contestación, según corresponda".

${ }^{23} \mathrm{El}$ artículo $493 \mathrm{del} \mathrm{CT}$, prescribe: "Cuando de los antecedentes aportados por la parte denunciante resulten indicios suficientes de que se ha producido la vulneración de derechos fundamentales, corresponderá al denunciado explicar los fundamentos de las medidas adoptadas y de su proporcionalidad".
} 
claramente en su obra cómo este supuesto principio ha encontrado el sustrato necesario para desarrollarse en las ideologías autoritarias o totalitarias, realizando un exhaustivo examen de la normativa procesal soviética y fascista ${ }^{24}$.

Para justificar lo anterior, y siguiendo la formulación efectuada por Goldschmidt, vale hacer presente en este punto, la clásica distinción efectuada en torno a lo que debe entenderse por deber, carga y obligación en el proceso.

El deber ha sido definido como "aquel imperativo legal establecido a favor de una adecuada realización del proceso, dirigido no tanto al interés individual de las partes como al interés de la comunidad" 25 .

A su vez, respecto de la carga procesal ha habido convergencia en la doctrina en entender que por medio de ese imperativo el sujeto está recomendado por el ordenamiento procesal, a la tarea de hacer progresar el proceso, a través de la ejecución de una conducta que a él le es útil, y cuya infracción o desembarazamiento solo afectará a su propio interés ${ }^{26}$.

Por último, respecto de la obligación, esta es un vínculo entre las partes, un imperativo del interés ajeno que supone la exigencia de un derecho correlativo, el cual puede exigir coactivamente el cumplimiento de la obligación, y en caso de incumplimiento, la reparación o indemnización consiguiente ${ }^{27}$.

De acuerdo con lo expuesto, y siguiendo la metodología utilizada por Carretta ${ }^{28}$, tenemos que las diferencias fundamentales entre las nociones de deber, obligación y carga pueden ser abordadas desde dos perspectivas. Primeramente considerando a quién beneficia una u otra noción, y en seguida, determinando a quién corresponde la exigibilidad derivada de su incumplimiento.

Respecto de la primera de dichas perspectivas, tenemos que, tratándose de un deber, este se impone en beneficio de la comunidad, en cambio respecto de la carga y la obligación, estas se imponen en beneficio de las partes ${ }^{29}$. En segundo lugar, respecto del incumplimiento del deber, tenemos que la sanción a dicho respecto viene impuesta por el Estado, que evidentemente es un sujeto distinto al infractor, el cual será una de las partes que intervengan en el procedimiento. Por su parte, tratándose de la carga y de la obligación, que como se señaló están establecidas en propio beneficio del sujeto y de las partes, quedando por ende a su entero arbitrio y voluntad el cumplir o no con ellas, su exigibilidad proviene del propio sujeto y de las partes, en el caso de la obligación ${ }^{30}$.

Como puede claramente apreciarse, la noción de deber apunta en este sentido al desarrollo y desenvolvimiento del proceso civil de una manera éticamente correcta, que es la que interesa al Estado, y así pone en evidencia el claro contenido axiológico y valorativo que no poseen los conceptos de carga y obligación.

\footnotetext{
${ }^{24}$ MONTERO AROCA, Juan, op. cit. (n. 17), pp. 15 y ss.

${ }^{25}$ PICÓ Y JUNOY, Joan, op. cit, , p. 33.

26 CarretTa Muñoz, Francesco, "Deberes procesales de las partes en el proceso civil chileno: Referencia a la buena fe procesal y al deber de coherencia", en: Revista Chilena de Derecho, vol. 21, $\mathrm{N}^{\circ} 1,2008$, p. 4. Disponible en: http:// www.scielo.cl/pdf/revider/v2ln1/art05.pdf [consultado el 10 de noviembre de 2009].

${ }^{27}$ Montero Aroca, Juan, op. cit. (n. 17), p. 47.

${ }^{28}$ CARRETTA MUNoz, Francesco, op. cit., pp. 5 y ss.

29 GOLDSCHMIDT, citado por CARRETTA MUÑOZ, Francesco, op. cit., p. 6.

${ }^{30}$ Ibid.
} 
De lo anterior, pareciese seguirse que el establecimiento de deberes positivos de actuación para las partes en el proceso civil, se contrapone con la idea de un proceso que, al erigirse como una garantía de los intereses y derechos de los ciudadanos, se construye necesariamente sobre la base de que los actos procesales que las partes desarrollen en él son para estas simplemente facultativos y no obligatorios. En este sentido, la idea de que las partes deban asumir ciertos deberes que puedan colocar en riesgo sus intereses, significa que el proceso deja de ser un instrumento destinado a la tutela de los derechos de las personas para ser un fin en sí mismo ${ }^{31}$.

Entendiendo a la buena fe como un deber de actuación positiva de las partes dentro del proceso, es que este se materializa, de acuerdo a Landoni ${ }^{32}$, de las siguientes formas:

- Brindando al tribunal la información veraz y completa de cómo ocurrieron los hechos, sin ocultamientos, reticencias o ambigüedades.

- Aportando la prueba de cargo y de descargo sin retaceos.

- Utilizando de forma correcta las vías procesales y no abusando de ellas para procurar fines ilícitos, no promoviendo procesos infundados, innecesarios, no utilizando vías inadecuadas, no deduciendo excepciones, incidentes o recursos maliciosos.

- Colaborando con el tribunal en el desarrollo del proceso y en especial de la audiencia, ya que la actividad conjunta del juez y las partes es esencial para lograr la efectiva tutela de los derechos sustanciales.

Como puede observarse, la idea de un deber de buena fe, con todos los demás deberes de ella derivados que se han señalado, y que se funda en la necesidad de que a través de esta se garantice el desenvolvimiento del proceso de modo ético y correcto en búsqueda de la justicia, se engarzan con la idea de que la finalidad del proceso civil es la satisfacción o la tutela de intereses del Estado o sociales, por cuanto es un instrumento para el bienestar social, y no con el debido resguardo y protección que merecen los intereses privados.

Así las cosas, es evidente que la implementación de un deber de buena fe a las partes que rija sus actividades y restrinja el juego dialéctico entre ellas no corresponde a una idea aislada ni a una mera opción técnica del legislador, por el contrario, de acuerdo con Montero Aroca, forma parte de un conjunto, de un sistema procesal que tiene un sentido determinado y que es fácilmente identificable en el que los derechos de las partes juegan un papel subordinado al interés prioritario estatal, manifestación concreta de autoritarismo en el cual los ciudadanos no tienen verdaderos derechos frente al Estado, sino únicamente deberes ${ }^{33,} 34$.

\footnotetext{
31 HUNTER AMPUERO, Iván, op. cit., p. 165.

32 LANDONi SOSA, Ángel, "El principio de moralidad: Base fundamental para un proceso justo", en: V.V. A.A., Tratado de buena fe en el derecho, tomo II, La Ley, Buenos Aires, 2004, p. 400.

33 En efecto, continúa señalando el autor, en un párrafo que recoge y pone en evidencia el trasfondo del deber de buena fe, señala ... "las repetidas alusiones a que el proceso es el medio para que las partes y sus abogados colaboren con el juez en la obtención de lo más justo, en el descubrimiento de la verdad o la justicia material, solo se comprende en un contexto ideológico que parte de dar por sobreentendido que los ciudadanos no tienen derecho a "pelear" por lo que crean que es suyo y a hacerlo con todas las armas que les proporciona el ordenamiento jurídico. Solo el juez autoritario, fascista o comunista, lo mismo da, es el juez que se cree ungido, por no se sabe muy bien qué fuerza de la divinidad o del destino, para hacer justicia entre los hombres. El juez liberal y garantista se limita, más modestamente, a pretender hacer efectivo el derecho positivo entre los ciudadanos, a aplicar la ley". MONTERo AROCA, Juan, "Sobre el mito autoritario de la "buena fe procesal", en: él mismo (coord.), Proceso civil e ideología, Tirant lo Blanch, Valencia, 2006, p. 337.
} 
Ello es de toda evidencia, ya que si el norte de todo proceso es la búsqueda de la verdad real, es decir, aquella necesaria como una condición de justicia, es perfectamente comprensible el aumento de las facultades del tribunal, lo cual no solo permite con más facilidad el alcance de la pretendida verdad material, sino que además apunta en convertir al juez en un fiscalizador respecto del cumplimiento de los deberes de buena fe y probidad de las partes en el proceso ${ }^{35}$.

En efecto, lo que se pretende es que, teniendo como estandarte la búsqueda de la "verdadera verdad", y estando obligados las partes y sus defensores a colaborar con el juez en esa búsqueda, prescindiendo absolutamente de sus intereses y derechos, deben además poner todas sus armas sobre la mesa, sin esbozar estrategia alguna para su defensa, por cuanto, por sobre sus viles intereses, existe un fin superior, que es la realización de la justicia, a la que solo se podrá acceder, estableciéndose con precisión y exactitud cómo efectivamente se verificaron los hechos en la realidad. De esa forma se responde al interés del Estado en la realización del derecho objetivo.

\section{CONSAGRACIÓN DEL DEBER DE LA BUENA FE Y EL CONFLICTO CON LAS GARANTÍAS CONSTITUCIONALES}

Entendiendo que nuestro Código del Trabajo impone efectivamente el despliegue respecto de las partes intervinientes del procedimiento, de conductas positivas orientadas al resguardo de la buena fe, en las normas previamente analizadas, y considerando, en consecuencia, que nos encontramos ante meros procedimientos, y no frente a procesos, es fácilmente verificable que mediante él se afectan una seria de garantías constitucionales.

a) La Buena Fe Procesal y el Derecho a Defensa: esta garantía constitucional se encuentra consagrada en el artículo 19 No 3 de la CPE y ha sido definida por Carocca, como aquella garantía que "resguarda la efectiva posibilidad de las partes de actuar en el proceso efectuando sus alegaciones y pruebas, permitiéndoles mantener una postura procesal determinada" 36 .

Siguiendo al mismo autor, el derecho a defensa se manifiesta en el reconocimiento a la vez de ciertos derechos específicos, que incluye los siguientes:

\footnotetext{
${ }^{34} \mathrm{Al}$ respecto, evidentemente desde la posición publicista del proceso se ha rebatido que en la actualidad, ninguno de los Códigos de Procedimiento Civil que consagran deberes positivos de buena fe para las partes, puede sostenerse de modo plausible que ellos formen parte de regímenes totalitarios o autoritarios, y que por el contrario, dichos cuerpos normativos han nacido en sociedades absolutamente democráticas, intentando de ese modo restar importancia y ridiculizar las críticas efectuadas por la corriente garantista. Ver en este sentido a TARUFFO, Michelle, "Poderes probatorios de las partes y el juez en Europa", en: Ius et Praxis, $\mathrm{N}^{\circ} 12$, Universidad de Talca, 2006.

Sin embargo, a lo que apuntan las críticas garantistas no es al hecho de que se trate actualmente de regímenes autoritarios, sino al hecho innegable de que efectivamente la imposición de deberes positivos de actuación de buena fe para las partes en el proceso, nació dentro de contextos autoritarios, por lo que se intenta alertar de los excesos por todos conocidos (fascismo, nazismo), a que se puede llegar siguiendo ese camino. No debemos pasar por alto tampoco la importancia de la crítica, considerando que los derechos de los ciudadanos se restringen y violan más sutilmente en Estados democráticos, situación que evidentemente, como se señalará a continuación, ocurre respecto de la consagración de deberes de buena fe que no solo coartan el libre juego dialéctico de las partes dentro del proceso, sino que además afectan una serie de otras garantías constitucionales, como el derecho a defensa.

${ }^{35}$ CARRETTA MUÑOz, Francesco, op. cit., p. 6.

${ }^{36}$ Carocca Pérez, Alex, Garantia Constitucional de la Defensa Procesal, Editorial J.M. Bosch, Barcelona, 1998, p. 93.
} 
- Plantear una pretensión, a través de la demanda o la reconvención.

- Conocer oportuna y adecuadamente las pretensiones de la contraria, mediante los actos de comunicación idóneos.

- Contradecir la pretensión que se dirige en contra de uno, mediante la contestación de la demanda. Esto es lo que se ha denominado principio del contradictorio o audiencia bilateral

- Acreditar las alegaciones efectuadas, mediante la aportación de los medios de prueba pertinentes. Este se conecta tanto con la posibilidad de realizar todo lo que la parte estime pertinente para obtener una resolución favorable a sus intereses, es decir, introducir hechos y justificar jurídicamente su pretensión, así como también comprende el derecho a probar sus afirmaciones.

- Exigir que las alegaciones efectuadas y las pruebas sean valoradas en la sentencia ${ }^{37}$.

Como puede colegirse entonces de la propia definición expuesta y sus manifestaciones concretas, el derecho a defensa se manifiesta como una posibilidad de actuar en el proceso, es decir, una parte puede actuar o abstenerse de hacerlo de acuerdo a si ello es o no favorable o adverso para su pretensión jurídica, y es esta característica propia de la garantía la que evidentemente se ve conculcada al establecerse obligaciones y deberes a las partes de intervenir en el proceso.

En efecto, en virtud del proclamado principio de la buena fe procesal, y al hecho anteriormente expuesto de que el mismo se consagra como un deber, es decir, que a través de él se exige a las partes actuaciones positivas como la de colaborar con el juez y la contraria en la búsqueda de la verdad, y de aportar todos los hechos y pruebas que obren en su poder, aun cuando ello sea perjudicial para su pretensión, evidentemente afecta el hecho de que el derecho a defensa se consagre únicamente como una posibilidad a la parte de actuar, lo que es plenamente concordante con el hecho de que en todo proceso, y aún más en el proceso civil, lo que tiene especial protección es que debe ser un medio de resguardo de los intereses de los ciudadanos.

Para justificar la limitación que el denominado principio de la buena fe realiza a la garantía de defensa, algunos autores publicistas han intentado buscar un supuesto fundamento constitucional de la buena fe, el cual a juicio de Picó i Junoy, se encuentra en el hecho de que ese derecho fundamental, como cualquier otro, no es absoluto y se encuentra sujeto a ciertas limitaciones, que en el caso concreto se vinculan a la debida protección que ameritan otras garantías como lo son la tutela judicial efectiva, la defensa, la igualdad y la de un proceso con todas sus garantías ${ }^{38}$.

Evidentemente lo anterior, esto es reconocer que puede imponer límites al derecho a la defensa para lograr dentro del proceso actuaciones leales éticas y veraces, y así lograr

\footnotetext{
37 Ibid., pp. 187 y ss.

${ }^{38}$ En efecto, el referido autor sostiene que respecto de la tutela judicial efectiva se plantea que cuando un litigante utiliza de forma distorsionada o torcida las normas procesales, dificulta que el juez pueda otorgar una efectiva tutela de judicial de los intereses en conflicto; respecto del derecho a defensa plantea que la actuación maliciosa de un litigante suele, la mayoría de las veces, estar dirigida a perjudicar el derecho a defensa de la contraria; respecto de la garantía de la igualdad de las partes señala que la actuación maliciosa es susceptible de romper este equilibrio de intereses que las leyes procesales establecen para hacer respetar la plena igualdad de trato entre ambos litigantes, etc. PICÓ y JUNOY, Joan, op. cit., pp. 23 y ss.
} 
una justicia adecuada, como bien señala Hunter ${ }^{39}$, no es aceptable en razón de que para que un derecho fundamental pueda ser limitado es necesario que tal limitación se encuentre justificada en otros derechos fundamentales o bien en otros valores y bienes constitucionalmente protegidos, y resulta claro que la buena fe procesal no tiene consagración constitucional de forma tal que, en caso de conflicto entre derecho a defensa y buena fe, deberá por su jerarquía necesariamente resolverse a favor del primero ${ }^{40}$.

Por otra parte, continuando con el conflicto que se verifica entre la exigencia de conductas positivas de actuación para las partes conformes con la buena fe procesal y el debido resguardo del derecho de defensa, tenemos que igualmente podría verse afectada una de las manifestaciones de dicha garantía constitucional, como lo es el denominado principio del contradictorio.

En palabras de Comoglio, el principio contradictorio es "aquel conjunto de reglas que, desde la constitución de la relación procesal hasta la decisión del juicio, disciplinan el diálogo abierto entre los sujetos en litis, en vista de un objetivo común, la elaboración del contenido de la sentencia" 41 . En consecuencia, la idea subyacente es que cada una de las partes desde su particular sentido de la verdad, acorde con los intereses que defiende, pueda manifestarle al juez el contenido de sus afirmaciones, de forma tal que este pueda determinar la verdad o la falsedad de las mismas.

Evidentemente, dentro de la libertad que implica el proceso descrito, de que cada parte pueda manifestar lo que estime pertinente a sus intereses frente a lo afirmado o declarado por la contraria mediante un acto equivalente, significa únicamente eso, esto es, una mera posibilidad y en ello se agota el derecho. De esta forma imponer deberes positivos de actuación claramente implica coartar esta garantía y la idea de libertad que ella lleva implícita.

Lo anterior se refuerza además por el hecho de que si bien se señala en el Código del Trabajo que contra la resolución que decrete una actuación como dilatoria procederá el recurso de reposición, no se exige motivación alguna en. la resolución, ni tampoco se consagra la posibilidad de un incidente contradictorio que permite acreditar efectivamente la mala fe en que supuestamente ha incurrido una de las partes, ya que la buena fe debe presumirse.

b) La Buena Fe Procesal y la Legalidad: Respecto de esta garantía constitucional, es fácilmente advertible un punto de conflicto de la misma con el deber de buena fe procesal en lo que respecta a la posible imposición de sanciones que puede conllevar la infracción al referido deber por una de las partes, específicamente los casos contemplados en el artículo 430 Código del Trabajo, que facultan al juez -como se señaló- para adoptar las medidas necesarias para impedir el fraude, la colusión, el abuso del derecho y las actuaciones dilatorias.

Principalmente la interrogante planteada dice relación con la posibilidad que tendrá el juez laboral de aplicar multas a aquel de los litigantes que actúe en contravención a la buena fe, ello por cuanto si bien en la historia de la ley se planteó la posibilidad de que el

\footnotetext{
39 Ver HUNTER AMPUero, Iván, op. cit., pp. 159 y ss.

40 Cachón Cardenas, Manuel, citado GorigoItla ABotT, Felipe, op. cit., p. 148.

41 Comoglio, Luigi Paolo, citado por HunTer Ampuero, Iván, op. cit., p. 168.
} 
artículo 430 Código del Trabajo, consagrara la posibilidad de que el juez multará al infractor en una cantidad de 1 a 15 UTM, finalmente ello no prosperó ${ }^{42}$.

El problema pudiese surgir ya que, de aprobarse el nuevo Código Procesal Civil que expresamente impone multas para sancionar al posible infractor a la buena fe procesal, considerando además que el Código del Trabajo faculta al juez a recurrir a dicho cuerpo legal en casos de vacío de la normativa laboral, pudiese ocurrir que el juez laboral, en virtud de la norma del 430 ya referida, aplicara al litigante en materia laboral, las sanciones del futuro CPC.

En principio creemos que ello no sería posible, ya que afectaría la legalidad establecida en el artículo 7 de la CPE, en el sentido de que el llamado en un estado democrático a la creación de ilícitos y sanciones para dichas conductas es únicamente el legislador, y en consecuencia, no pudiese el juez arrogarse facultades legislativas, ya que a este solo le corresponde la tarea de imponer las sanciones ya establecidas previamente en la ley.

Además del principio de legalidad ya expuesto, se afectaría de paso la garantía de la legalidad en materia sancionatoria, contenida en el artículo 19 No 3, que implica que ninguna ley podría establecer penas sin que la conducta que se sancione esté expresamente descrita en ella, ya que si bien el citado artículo se refiere únicamente a delitos y faltas, siguiendo a Gorigoitía pareciera ser que este debe ser un principio aplicable a todo el ámbito del derecho sancionatorio, incluyéndose en él las multas que pudiesen imponer los tribunales ${ }^{43}$. Ello por cuanto, las sanciones sin una restricción de los derechos de los ciudadanos, de esta forma se permite y asegura a los mismos su debido respeto, conociendo de antemano los riesgos a los que se podrían exponer de incurrir en una determinada conducta no querida, con independencia del ámbito del derecho en que se aplique.

Resulta de facilidad advertir que el Código del Trabajo no señala de modo expreso qué entiende por colusión, fraude o abuso del derecho, por lo que establecer multas sobre conductas que no se han tipificado expresamente, a las claras vulnera el principio antes dicho. En el mismo sentido, parece que tampoco el término de la buena fe, cuya indeterminación conceptual ha sido reconocida por la mayoría de la doctrina, permita tampoco superar esta dificultad.

\section{CONCLUSIONES}

La buena fe es un concepto difuso e indeterminado, que pareciese a su vez, por su alto contenido ético y axiológico, calzar perfectamente con el zapato de lo que se ha venido conociendo como el fenómeno de la publicitación del proceso.

De esa forma, pareciese ser que el pretendido principio de la buena fe procesal no es más que otro instrumento para poder alcanzar la finalidad intrínseca que dicha corriente atribuye al proceso civil, que no es más que la pretendida búsqueda de la verdad real, la

\footnotetext{
42 Véase nota 9.

43 GORIGOITIA ABOTT, Felipe, op. cit., p. 147.
} 
cual supuestamente será alcanzable, dotando a los jueces de mayores poderes que les permitan determinar la verídica concatenación de hechos verificables, como asimismo, estableciendo verdaderos deberes para los litigantes, por medio de los cuales estos se ven compelidos a colaborar con la contraria y el juez en la búsqueda de ese fin, declarando y afirmando en el proceso todo lo que se encuentre a su disposición, y olvidando en consecuencia que lo que primeramente los motivó a concurrir al tribunal fue precisamente obtener una solución a su conflicto de interés.

Esta concepción, como lo señalé, parte de la base equivocada de que en algún momento los litigantes y sus respectivos abogados deban de reconocer que por el proceso ya no se trata de perseguir su beneficio, sino de asumir el carácter público del proceso y de colaborar con el juez en la búsqueda de la "justicia", aun cuando sea en contra de los propios intereses ${ }^{44}$. Sin embargo, esta posición pareciese olvidar que realmente el proceso es un instrumento por medio del cual las partes ante un tercero imparcial exponen su propia verdad, limitándose la actividad jurisdiccional a verificar la exactitud de lo declarado en contraste con lo probado por cada una de aquellas.

Como señala Cipriani ${ }^{45}$, no es que se consagre un derecho a mentir, ni que se quiera proclamar la mala fe del proceso, pues esas ideas también surgen de un contexto autoritario en que se desconfía de los abogados, no solo en el sentido de que no serán capaces de defender correctamente el interés de su parte, sino además en el sentido de que por su incapacidad recurrirán a toda clase de artilugios ilícitos para obtener la victoria.

Si bien las referencias a la buena fe procesal pueden ser loables, debe ponerse especial énfasis en la forma en que ella es protegida dentro de los ordenamientos procesales civiles, por cuanto el establecimiento de deberes positivos de actuación para las partes es limitativo de sus garantías, debiendo en consecuencia únicamente imponerse deberes de abstención de actuar de mala fe dentro del proceso.

Lo anterior, sobre todo de considerarse el hecho de que el proceso civil se trata en el de que cada una de las partes, en un juego libre de dialéctica, desde su peculiar visión de lo ocurrido, trate de justificar su verdad particular y obtener en definitiva una sentencia favorable a sus intereses. Conforme a ello, y, entendiendo al proceso civil en esa forma, es posible percatarse que dentro de él ya existen instituciones que permiten por sí mismas verificar la falsedad o veracidad de lo afirmado por las partes como lo es la propia prueba que se rinda que debe ser contrastada con lo afirmado por cada parte, o el propio contradictorio que permite también asegurar a cada una de las partes, en caso que la otra haya faltado a la verdad en su relato, afirmar y probar lo contrario, sin que de modo alguno sea necesario ni justificable imponer a las partes deberes positivos de actuación, que únicamente contribuyen a coartar su libertad y sus derechos.

\footnotetext{
${ }^{44}$ MONTERo AROCA, Juan, op. cit. (n. 17), p. 41.

45 Cipriani, Franco, "El abogado y la verdad", en: MONTERo Aroca, Juan (coord.), Proceso civil e ideologia, Tirant lo Blanch, Valencia, 2006, pp. 284 y ss.
} 
María Matilde Larroucau García / La buena fe procesal y el deber de colaboración de las partes en los procedimientos laborales

\section{BIBLIOGRAFÍA}

Benf́teZ RAmírez, Eugenio, "Reflexiones en torno a la propuesta de reforma al Procedimiento Civil Chileno: II. Principios Procesales relativos a las partes", en: Revista Chilena de Derecho, vol. $34, \mathrm{~N}^{\circ} 3$, 2007. Disponible en: http://www.scielo.cl/scielo.php?pid=S0718-34372007000300014\&script= sci_arttext [consultado el 10 de noviembre de 2009].

Carocca Pérez, Alex, Garantía Constitucional de la Defensa Procesal, Editorial J.M. Bosch, Barcelona, 1998.

CARretta Muñoz, Francesco, "Deberes procesales de las partes en el proceso civil chileno: Referencia a la buena fe procesal y al deber de coherencia", en: Revista Chilena de Derecho, Vol. 21, N 1, 2008. Disponible en: http://www.scielo.cl/pdf/revider/v21n1/art05.pdf [consultado el 10 de noviembre de 2009].

CIPRIANI, Franco, "El abogado y la verdad", en: MONTERo AROCA, Juan (coord.), Proceso civil e ideologia, Tirant lo Blanch, Valencia, 2006, pp. 283-291.

DE ÁNGEL YAGƯEZ, Ricardo, "Una expresión de lo que no es buena fe: El ejercicio malicioso de acciones judiciales. Jurisprudencia española de las dos últimas décadas", en: V.V. A.A., Tratado de buena fe en el derecho, tomo II, La Ley, Buenos Aires, 2004, pp. 421-450.

GOMEZ POZUETA, Carlos, La buena fe procesal. Disponible en: http://noticias.juridicas.com/articulos/60Derecho\%20Procesal\%20Civil/200903-58796203120475.html [consultada 12 de noviembre de 2009].

Gorigoitía AвOTT, Felipe, "La buena fe en el proceso civil chileno", en Revista Nomos, $\mathrm{N}^{\circ} 2$, 2008, Universidad de Viña del Mar, pp. 133-159.

HUNTER Ampuero, Iván, "No hay buena fe sin interés: La buena fe procesal y los deberes de veracidad, completitud y colaboración", en: Revista de Derecho, vol. XXI, N², 2008. Disponible en: http:// www.scielo.cl/pdf/revider/v2 1 n2/art07.pdf [consultada 8 de noviembre de 2009].

LANDONI SOSA, Ángel, "El principio de moralidad: Base fundamental para un proceso justo", en: V.V. A.A., Tratado de buena fe en el derecho, tomo II, La Ley, Buenos Aires, 2004, pp. 391-420.

MARTI MARTI, Joaquín, Responsabilidad Extracontractual por actuación negligente. Disponible en http:// www.bufetejmarti.com/Documenta/Actuacionjudicialnegligente.htm [consultada 12 de noviembre de 2009].

Monteleone, Girolamo, "Principios e ideologías del proceso civil: Reflexiones de un 'revisionista'. Disponible en http://www.egacal.com/upload/JMA_Monteleone01.pdf [consultada el 12 de noviembre de 2009].

Monteleone, Girolamo, "El actual debate sobre las "orientaciones publicísticas" del proceso civil", en: Montero Aroca, Juan (coord.), Proceso civil e ideologia, Tirant lo Blanch, Valencia, 2006, pp. 173197.

MONTERO AROCA, Juan, Ideologia y proceso civil. Su reflejo en la "buena fe procesal". Disponible en: www.cadperu.com/virtual/file.php/1/moddata/data/3/.../IDEOLOGIA.pdf [consultada 8 de noviembre de 2009].

Montero Aroca, Juan, "Sobre el mito autoritario de la 'buena fe procesal', en: él mismo (coord.), Proceso civil e ideologia, Tirant lo Blanch, Valencia, 2006, pp. 293-353.

MONTERo AROCA, Juan, "El proceso civil llamado "social como instrumento de "justicia" autoritaria", en: él mismo (coord.), Proceso civil e ideologia, Tirant lo Blanch, Valencia, 2006, pp. 129-165.

PALAVECINO CACERES, Claudio, "El retorno del inquisidor. Las potestades judiciales en materia probatoria en el Procedimiento laboral chileno", en: Revista Laboral Chilena, $\mathrm{N}^{\circ} 173$, enero 2009, Santiago, pp. 73-85. 
PICO i JUNOY, Joan, El principio de la buena fe procesal. Disponible en: http://www.justiciayderecho.org/ revista 4/articulos/EL\%20PRINCIPIO\%20DE\%20LA\%20BUENA\%20FE\%20PROCESAL\%20 Joan\%20Pico\%20i\%20Junoi.pdf

PICO i JUNOY, Joan, El derecho procesal entre el garantismo y la eficacia: Un debate mal planteado, en: Montero Aroca, Juan (coord.), Proceso civil e ideologia, Tirant lo Blanch, Valencia, 2006, pp. 109127.

SENTIS MELENDO, Santiago. Desarrollo del proceso, deberes del juez y cargas de las partes. Disponible en: http:/ /www.juridicas.unam.mx/publica/librev/rev/boletin/cont/24/art/art23.pdf [consultada 16 de noviembre de 2009]

TARUfFo, Michelle, "Poderes probatorios de las partes y el juez en Europa"; en: Ius et Praxis, $\mathrm{N}^{\circ} 12$, Universidad de Talca, 2006. pp. 95-206.

\section{LEYES CONSULTADAS}

Anteproyecto de Código Procesal Civil. Disponible en: http://www.derecho.uchile.cl/cej/recej/recej8/ documentos.htm [consultada 25 de diciembre de 2009].

Historia de la Ley 20.260. Disponible en: http://recursoslegales.ben.cl/jspui-rl/bitstream/10221.3/503/1/ HL\%2020260.pdf [consultada 8 de noviembre de 2009].

Historia de la Ley 20.087. Disponible en: http://recursoslegales.ben.dl/jspui-rl/bitstream/10221.3/565/1/ HL20087.pdf [consultada 8 de noviembre de 2009].

Código Procesal Civil de Perú. Disponible en: http://vlex.com.pe/vid/codigo-procesal-civil-42814988 [consultada 25 de diciembre de 2009].

Ley de Enjuiciamiento Civil Española. Disponible en: http://civil.udg.es/normacivil/estatal/LEC/L1T8.htm [consultada 25 de diciembre de 2009].

Ley Procesal Civil Alemana (ZPO). Disponible en: http://www.kas.de/wf/doc/kas_9523-544-4-30.pdf [consultada 25 de diciembre de 2009]. 